\title{
Sócrates según Nietzsche
}

\author{
Greta Rivara Kamaji
}

$\mathbf{N}$

o son pocas las ocasiones en las que la figura de Sócrates aparece glorificada, mucho de lo que se ha dicho de él resulta apologético. Sócrates suele aparecer como un gran mártir de la filosofía, de la política griega, víctima de su propia sabiduría, hombre fiel a sus principios hasta la muerte. Se ha resaltado su actitud ejemplar en la vida y en el momento de su muerte y se le ha concebido como un sabio casi espontáneo, ejemplo de vida para el resto de los mortales. Es larga la lista de autores e intérpretes que lo han exaltado, ${ }^{1}$ aun hoy glorificamos al filósofo que no sólo no escribió una sola línea sino que se negó a hacerlo. A diferencia de muchos, Nietzsche se atrevió, como con prácticamente todo lo que le salió al paso, a problematizar la figura de Sócrates, a entablar una violenta polémica con el mundo mismo que vio nacer a Sócrates y su modo de pensar. Para Nietzsche, Sócrates no es un individuo aislado, ejemplar, sino que es símbolo de un mundo, de una cultura, de una manera de ver la vida. Así, al violentar Nietzsche la sagrada imagen de Sócrates y al atreverse a criticar y a poner en cuestión su valor y su alcance, lo hace con el fin de volver a reflexionar sobre la Grecia de Sócrates, tan equívocamente entendida por los filólogos del XIX, ${ }^{2}$ sobre esa Grecia de Eurípides, de Platón, de la muerte de la tragedia y del nacimiento de los más altos valores que, según Nietzsche, Occidente detentaría: la razón y el conocimiento.

Si Nietzsche cuestiona a Sócrates y se detiene en él sin deificarlo, es porque con él necesitaba problematizar la visión socrática del mundo que, más

${ }^{1}$ Obviamente, con esto no se desconoce el valor y la calidad de intérpretes como Taylor, Burnet y Maier, entre otros.

2 Entre ellos el propio Wilamowitz, quien efectuó contra Nietzsche una feroz crítica, precisamente por la visión del mundo griego que planteaba en El nacimiento de la tragedia. 
allá de Sócrates, se convierte en una idea del mundo y del hombre en la filosofía misma.

Si Nietzsche no permaneció hincado adorando al hombre que sentenciaba que una vida sin autoexamen no vale la pena de ser vivida, es justo porque su crítica no trata de Sócrates mismo, a fin de cuentas ¿quién fue Sócrates? Sería ocioso discutir si Nietzsche le hizo o no justicia; Sócrates era para él sólo un modelo, un símbolo de algo que le parecía más importante reflexionar: las implicaciones de la visión socrática de la vida. Implicaciones en las que, además, vio posibilidades insospechadas aun para los mismos apologetas de Sócrates: el Sócrates músico. Aun con toda la violencia de la crítica de Nietzsche a Sócrates, ésta es más provechosa que la pura exaltación acrítica; ni lo idolatra, ni lo destruye: lo problematiza, y con él, a la historia de la filosofía, pero, no sólo eso, sino que también hace surgir una de sus más fértiles propuestas: la del Sócrates músico.

Con todo, el problema "Sócrates" surge en medio de la visión nietzscheana de la tragedia griega. Ésta se convierte en El nacimiento de la tragedia en el tema capital del pensamiento de Nietzsche, que comienza a desarrollarse con categorías estéticas; la tragedia es el modelo a partir del cual Nietzsche trata de pensar el ser de la vida, y es en este camino en el que se encuentra con Sócrates; la tragedia como expresión del ser en términos dionisiaco-apolíneos será confrontada con la visión socrática del mundo.

Según Nietzsche, la tragedia es sustituida por la completud del nuevo hombre, simbolizado en Sócrates, el hombre teórico. Éste sólo ha podido surgir cuando los instintos griegos trágicos decaen y se enferman, de hecho, hay dos verdades puestas en juego en El nacimiento de la tragedia y que se enfrentan violentamente: la verdad de la tragedia y la verdad socrática. La verdad de la tragedia radica en que ésta nos descubre el fondo dionisiaco de la vida, su fondo oscuro y abismal, mientras que la verdad socrática empobrece este fondo al subsumirlo a la luz de la razón. Si la tragedia nos podía conducir a la vida en su entraña dionisiaca, a su sustento instintual y su manifestación en ilusiones nobles, apolíneas, Sócrates pretende, según Nietzsche, que la razón haga inteligible y coherente el absurdo insoportable de la existencia. Ésta es la ilusión socrática, opuesta a la ilusión trágica-apolínea expresada en la tragedia, en la cual el dios del sueño desciende para fundirse con Dioniso en su caoticidad amorfa. Los griegos trágicos supieron reconocer, precisamente en su tragedia, que el mundo luminoso de la ficción apolínea se une en un lazo irrompible con el Hades, reconocieron que en la bella apariencia subyace el fondo terrible de la existencia, sólo así, dice Nietzsche, podían soportarla, en los esponsales de Dioniso con Apolo, en la transmutación del carácter absurdo de la existencia que el arte trágico fue capaz de hacer. El arte y no la razón como luego pensaría Sócrates; quien fuera el mejor espectador 
de la tragedia de Eurípides, quien asumiendo y representando el universo socrático olvida el sustento dionisiaco de la transfiguración apolínea, llevando con ello a la tragedia a su punto final.

Dioniso había sido ahuyentado ya de la escena trágica y lo había sido por un poder demónico que hablaba por boca de Eurípides. También Eurípides era, en cierto sentido, solamente una máscara: la divinidad que hablaba por su boca no era Dioniso ni tampoco Apolo, sino un demón que acababa de nacer llamado Sócrates. Ésta es la nueva antítesis: lo dionisiaco y lo socrático, y la obra de arte de la tragedia pereció por causa de ella. ${ }^{3}$

Sócrates y Eurípides son vistos por Nietzsche como verdugos de la verdadera expresión trágica, de la verdadera expresión de la vida como instinto; ellos terminan con la tragedia, fin que da nacimiento al mundo del concepto. El mundo del hombre trágico cede su verdad al hombre teórico, autosuficiente. En esta visión la vida pierde su herida básica, su oscuridad y su sombría luminosidad, la unidad vida-muerte se conceptualiza. El fondo vital instintivo, poderoso, profundo se convierte ahora en el aseguramiento de la vida captada desde el conocimiento que había de negar estos instintos; y si algún instinto asumió Sócrates fue, según Nietzsche, el de convertir todo en algo pensable, dominable por la razón, aun la existencia misma. Así, Sócrates pensó que la razón es capaz de llegar hasta los abismos últimos del ser, éste es el desenfreno del instinto socrático, tornarlo todo en teoría; "en la persona de Sócrates -aquella inconcusa creencia de que, siguiendo el hilo de la causalidad, el pensar llega hasta los abismos más profundos del ser, y que el pensar es capaz no sólo de conocer, sino incluso de corregir el ser". ${ }^{4}$

El artista trágico que apostaba por la esencia creadora del hombre y sus posibilidades de transfigurar la existencia para poder habitarla, para poder modelar su ser transmutando lo más horrible en lo más bello, deja de ver la vida como el devenir de lo apolíneo-dionisiaco y hace depender la vida de la unilateralidad de la razón socrática que se convierte en moral, en el imperativo de buscar explicar la vida satisfaciendo la nueva conciencia, la conciencia que conoce y domina la existencia.

El socratismo racional de Eurípides asesina la tragedia, la visión del mundo que aquél inaugura se traduce en un vacío y silencioso optimismo, en una confianza desmedida en el concepto que ahogaría la intuición del artista trágico. ${ }^{5}$

${ }^{3}$ Friedrich Nietzsche, El nacimiento de la tragedia. México, Alianza, 1995, p. 109.

${ }^{4}$ Ibid., p. 127.

${ }^{5}$ A este respecto, Nietzsche afirma que: "[...] Sócrates es el prototipo del optimis- 
Con esto, el Sócrates que dibuja Nietzsche abre el horizonte del problema del racionalismo que venía a aniquilar la visión trágica-dionisiaca del mundo. La ilusión socrática se sustenta en el hecho de racionalizar la vida, pero para Nietzsche no toda ilusión vale por igual, ésta, la de Sócrates, no corresponde a la óptica de la vida que sería para Nietzsche el parámetro de validez y utilidad de las ilusiones. En la ilusión socrática, la vida entendida desde Dioniso abandona la escena, la óptica misma de la vida ya no funge como creación de ilusiones; la razón se separa de la vida. Y no es que Nietzsche haya negado en general el valor de la razón, sino sólo de aquella que inauguraría Sócrates, aquella que se opone al instinto, al reconocimiento del sustrato dionisiaco de la vida. Por esto, Sócrates es la figura que le permite a Nietzsche sacar a la luz el conflicto entre instinto y razón que ha guiado, según él, al pensamiento occidental, quien ha privilegiado a una por encima del otro. Conflicto que no representa por sí mismo nada, sino que su importancia radica en lo que se encuentra detrás de él, en la incapacidad de la razón, vista socráticamente, de vincularse con la vida y surgir de ella y desde ella.

Este conflicto no estaba planteado en la tragedia helena según Nietzsche, los griegos trágicos sabían que el instinto es razón y que también es creador y transfigura la existencia, que transfigura el dolor de la finitud en arte, en alegría. El sueño y la embriaguez del artista apolíneo-dionisiaco crea, transfigura para poder vivir; genera un equilibrio entre el núcleo primordial de la vida y sus posibilidades creadoras y esto es lo que precisamente, según Nietzsche, viene a romper Sócrates creando aquel conflicto, conflicto que, en realidad, no se mantiene porque excluye al instinto y da prioridad por sobre él a la razón. La música dionisiaca que sale del infierno ya no acompaña las representaciones apolíneas, ahora es la razón que acompaña la intelección del mundo, no su creación, no su transfiguración, no su abrazo fatal, no el abrazo de Dioniso con Apolo. ${ }^{6}$

Lejos de ello, Sócrates que habla por la boca de Eurípides y a la inversa, se convierte en un educador, nos enseña que la razón puede ultrapasar las contradicciones y abismos de la existencia, que puede entender y comprender el avasallante devenir que nos constituye y más aún, atraparlo. En este sentido, cabe preguntar si es la desmedida confianza en la razón y la poca confianza en

mo teórico que, con la señalada creencia en la posibilidad de escrutar la naturaleza de las cosas concede al saber y al conocimiento la fuerza de una medicina universal, y ve en el error el mal en sí. Penetrar en esas razones de las cosas y establecer una separación entre el concepto verdadero y la apariencia y el error, eso parecióle al hombre socrático la ocupación más noble de todas [...]" (F. Nietzsche, op. cit., p. 129).

${ }^{6}$ Nietzsche es categórico al respecto: "El socratismo desprecia al instinto y, con ello, al arte" (ibid., p. 222). 
la vida por parte de Sócrates lo que le hace a Nietzsche rechazarlo y convertirlo en símbolo de decadencia de los instintos griegos. Desconfiar del instinto es para Nietzsche desconfiar de la vida, y con ella, del hombre y del modo en el que el ser se despliega y manifiesta en él. Es importante señalar que es realmente el abuso de la razón lo que preocupa a Nietzsche. Sólo en esto radica, en la visión nietzscheana, la imagen de Sócrates como problema, pero justo esto es lo que le hace ignorar otras dimensiones de Sócrates, de su persona y de su pensamiento, que otros autores han rescatado, aunque a veces miope y acríticamente. La lucha de Nietzsche no es con Sócrates sino con lo que éste representa; la lucha de Nietzsche es poder afirmar que no es necesariamente la pura razón la que nos hace conocer la vida, más bien es la vida y no la razón del hombre la que dicta sus propias medidas a través de sus instintos, y ello no puede ser sustituido por el concepto, del cual, según Nietzsche, Sócrates es el genial inventor, inventor con ello del miedo al instinto, del miedo que le hace imaginar que su fuerza, la del instinto, puede ser dominada por otra fuerza, la de la razón. ¿Es entonces Sócrates para Nietzsche un peligro, o es a través de él que nos avisa de un peligro, el de reducir la vida a la razón? ¿O acaso Nietzsche ve a Sócrates sólo ya desde la óptica con la que considera al pensamiento posterior, el cual deduce de Sócrates y que no necesariamente está en él? ¿Es Sócrates quien sustituye la totalidad de la vida como dolor y alegría por la identificación entre razón y virtud o es más bien la guerra que Nietzsche declara a cualquier actitud que pretenda realizar aquella sustitución? ¿Es Sócrates realmente el que quiere resolver la ambigüedad de la existencia con la razón? ¿Es responsable Sócrates de que Eurípides no encauzara los presupuestos nietzscheanos en torno a la vida en su tragedia? Podríamos pensar que Nietzsche parece mezclar todo, medir todo con la misma vara, la suya.

Pero, sobre todo, parece que lo que más molesta a Nietzsche de Sócrates es algo que no necesariamente está explícito en su crítica: el moralismo intelectual de Sócrates, también expresado, según Nietzsche, en el mismo Eurípides. Eurípides moraliza la tragedia y con ello moraliza su visión del mundo, visión en la que Dioniso no tiene más cabida, la sabiduría dionisiaca es sustituida por el racionalismo socrático que maquilla el ser de la vida, que lo pasa por la sartén de la razón; la Gorgona se pone la máscara, Dioniso se oculta, Apolo también. Sócrates hace de la felicidad, según Nietzsche, una cosa mediocre, la moraliza, se convierte en la praxis del hombre virtuoso, del hombre teórico.

La conciencia socrática y su optimista creencia en la unión necesaria entre virtud y saber, entre felicidad y virtud, tuvo, en un gran número de piezas euripídeas, el efecto de que, en la conclusión, se abra una perspectiva hacia una existencia ulterior muy agradable, casi siempre con un matrimonio. Tan pronto como aparece el dios de la máquina, 
advertimos que quien se esconde detrás de la máscara es Sócrates, el cual intenta equilibrar en su balanza la felicidad y la virtud. Todo el mundo conoce las tesis socráticas "la virtud es el saber: se peca únicamente por ignorancia. El virtuoso es el feliz". ${ }^{7}$

El instinto ya no es fuente de felicidad para Sócrates, es el ignorante, es decir, el que cree que sabe quien actúa por instinto. De este modo, Sócrates, según Nietzsche, despreció el valor del instinto para la vida y valoró al conocimiento y a los aspectos racionales de la vida por encima de cualquier otra dimensión. El ojo ciclópeo de la razón ${ }^{8}$ es, para Sócrates, la única instancia que no sólo nos hace virtuosos y felices, sino con la cual podemos resistir al instinto.

Según Nietzsche, Sócrates convirtió al instinto, en esencia afirmador y creador, en una instancia subordinada a la razón reconociendo de la vida sólo una de sus dimensiones y no la totalidad y pluralidad de fuerzas que constituyen su dinamismo. Ahora bien, si nos queda claro que Nietzsche pretendía ver en Sócrates un símbolo, una metáfora del racionalismo moral, y no ningún Sócrates real, histórico, cabe decir que Nietzsche con Sócrates señala la soberbia de la razón, aquella que supone que puede conocer los abismos de la vida por sí misma. No es que con su crítica a Sócrates, Nietzsche niegue la razón sino que cuestiona su afán de reducir la vida a ella despreciando los instintos creadores como actores esenciales de nuestra vida. El hombre no vive, como según Nietzsche pretendía Sócrates, en el puro y absoluto ejercicio de la razón, sin escuchar nunca otras dimensiones de su ser. La vida rebasa el orden y la mesura en la que el socratismo pretendió encajonarla. La transfiguración apolínea de lo dionisiaco se convirtió en puro orden y pura mesura. Ahora bien, Nietzsche pretendió ser con Sócrates más benévolo de lo que Sócrates mismo fue con la vida. Nietzsche habla de un Sócrates músico, un Sócrates que de alguna manera cristalizaría los anhelos nietzscheanos de reconstruir la unidad entre razón e instinto. ${ }^{9}$

La vida para Nietzsche vale por sí misma, no sólo en tanto conocida teoréticamente o en tanto moralmente asumida como autoexamen, ¿pero pudo Só-

\footnotetext{
${ }^{7}$ Ibid., p. 227.

${ }^{8}$ Aquel ojo, al que "le estaba vedado mirar con complacencia los abismos dionisiacos" (ibid., p. 119).

${ }^{9}$ Una de las líneas más claras en torno a esta posibilidad del Sócrates músico se encuentra expresada en El nacimiento de la tragedia, en forma muy ambigua: "Y aun cuando es muy cierto que el efecto más inmediato del instinto socrático perseguía una descomposición de la tragedia dionisiaca, sin embargo una profunda experiencia vital de Sócrates nos fuerza a preguntar si entre el socratismo y el arte existe necesariamente tan sólo una relación antipódica, y si el nacimiento de un "Sócrates artístico" es en absoluto algo contradictorio en sí mismo" (ibid., p. 123).
} 
crates asumir también que la vida vale por sí misma? ¿Hay en el Sócrates músico una posibilidad de reunificar razón e instinto? ¿No es acaso el profundo sentido práctico, vivencial, del pensamiento de Sócrates una muestra de ello? Nietzsche mismo parece haberlo intuido con la idea del Sócrates músico, idea ciertamente sólo sugerida, apenas asomada pero de insospechadas resonancias en el pensamiento nietzscheano. ¿No es esta idea un hito representativo del mismo pensamiento de Nietzsche y sus propuestas? Cabe preguntar al respecto ¿cómo es que Nietzsche sería capaz de incluir en sus propuestas al Sócrates músico si su rechazo a éste fuese total e irreflexivo como suele pensarse? ¿No hay en la mayéutica socrática, en el mismo autoexamen, un poderoso despliegue de la afirmación de nuestro ser entendido como fuerza, como fuerza interior?

Hay aspectos dionisiacos en Sócrates, en el Sócrates artista de la vida y Nietzsche los vislumbró: la profunda vitalidad de la praxis socrática de reflexión interior, el afán y la necesidad de actuar conforme a la vida, es decir, Sócrates pudo haber llevado a Dioniso a la reflexión al dar a su pensamiento un carácter creador y reflexivo a la vez, sin reducir la vida a concepto pero sin aceptar tampoco que se diluya en la pura oscuridad abismal de las entrañas de lo dionisiaco.

¿Es entonces Sócrates o es Nietzsche quien radicaliza la lucha entre razón e instinto? ¿No es acaso el propio Sócrates quien hace del conocimiento una noble ilusión como quería Nietzsche? Sócrates supo que el conocimiento sin praxis vital no puede ser la medida de todas las cosas, este saber socrático es creador, artístico, es en este punto en donde el personaje ridiculizado por Nietzsche se convierte para él mismo en una de las más altas posibilidades de la filosofía de la aurora. Entonces, ¿por qué Nietzsche decidió inclinar el peso de sus dudas hacia la posibilidad de que el conocimiento socrático pudiera surgir desde la experiencia dionisiaca de la vida si tenía en Sócrates la intuición del filósofo artista? Tal vez porque Nietzsche no buscó en El nacimiento de la tragedia las posibilidades de la verdad más allá del arte, mientras que Sócrates sí lo hizo. ¿No es Sócrates acaso también un pensador de la experiencia de la irracionalidad y plantea su verdad para la vida, pero plantea a su vez la necesidad de conocer esa verdad para que la vida no se nos escape? Parece que Nietzsche abandonó su intuición del Sócrates músico, sin embargo, podemos decir que si bien su crítica a Sócrates en ocasiones parece insostenible, también podemos decir que Nietzsche honra al espíritu socrático mucho más que quienes sin mayores cuestionamientos han sobreestimado a aquel griego que nunca escribió sus pensamientos. ¿No aprendió Nietzsche de Sócrates algo que sería la esencia de su pensamiento: la crítica, la duda, la pregunta, el cuestionamiento, a veces irónico, a veces devastador para parir con ello verdades útiles para la vida? 